\title{
REDUCTION OF GROUND VIBRATIONS BY IMPROVING SOFT GROUND
}

\author{
Eirchi Taniguchi* and Susumu Okada**
}

\begin{abstract}
The countermeasures to ground vibrations generated by car traffic are summarized and among them the detail of the soft ground improvement is described in this paper.

The field tests and the finite element analyses were performed on the reduction of ground vibrations by soft ground improvement. At the field tests the ground was improved at region of $20 \mathrm{~m}$ in width, $30 \mathrm{~m}$ in length and $12 \mathrm{~m}$ in depth by lime pile method and the ground vibration test was conducted by using a vibration generator.

The finite element analyses were carried out to confirm that the finite element technique is useful to treat the surface wave propagation problem and to develop a prediction method of the reduction of traffic-induced vibration by improving the soft ground.

The following conclusions were obtained: i) The improvement of soft ground is effective to reduce the traffic-induced vibrations. The reduction of ground vibrations were observed in the frequency range less than $10 \mathrm{~Hz}$. ii) The width of the improvement area has small influence and the depth of the improvement area and the ratio of rigidity before and after improvement have large influence on the reduction of ground vibrations. iii) The predominant frequency of the ground was slightly increased by the construction of lime piles in the ground. iv) The calculated acceleration by the finite element analysis well agreed with measured values of the field tests. Therefore it is possible to simulate the ground vibration generated by a dynamic load on the ground surface by the finite element analysis. v) The reduction of traffic-induced vibrations can be evaluated by using a prediction figure presented in this paper.
\end{abstract}

Key words: field test, highway, soft ground, soil stabilization, vibration, wave propagation

IGC: $\quad$ E 8/D 7

\section{INTRODUCTION}

General Remarks

The ground vibrations generated by car traffic or a kind of vibratory machine sometimes cause damage to people and buildings near the source. Some countermeasures are considered to be effective to reduce the ground vibrations. Improving soft ground by sand compaction method or lime pile method etc. is one of these countermeasures and it can be imagined that this method is useful to decrease ground vibrations. Although the sand

* Research Engineer, Soil Dynamics Division, Public Works Research Institute, Ministry of Construction, Tsukuba Science City, Ibaraki, 305.

** Research Engineer, Kisojiban Consultants Co., Ltd., 2-14-1 Ishikawa-cho, Ohta-ku, Tokyo. Written discussions on this paper should be submitted before April 1, 1982. 
compaction or lime pile method are usually used to increase the shearing resistance of the ground soils, the rigidity of the ground is also increased and the amplitude of ground vibrations decreases with the increase of the rigidity of the ground.

It has not been clarified how much the amplitude of ground vibrations can be reduced by improving soft ground by construction of certain sized sand or lime piles in the ground. The purpose of the investigations described here is to obtain quantitative information on the reduction of ground vibrations by soft ground improvement. This paper mainly deals with the traffic-induced vibrations and the lime pile method is used in the field test but the results obtained here are applicable to other vibration problems and other improving methods of the soft ground.

\section{Countermeasures to Traffic-Induced Vibrations}

Countermeasures to traffic-induced vibrations can be divided into two groups; one is the countermeasure to the source of vibrations and the other is applied to the propagation path of vibrations. It is thought at the present that the following countermeasures are effective to reduce the traffic-induced vibrations.

a) to source of vibrations

i) keeping the smoothness of the surface of road pavement

ii) traffic flow control

iii) improving the road structure

b) to the propagation path of vibrations

i) construction of environmental zone

ii) improvement of soft ground

iii) setting up isolating barrier in the ground

i) Keeping the smoothness of the surface of road pavement

In these several countermeasures mentioned above the most effective one is keeping the smoothness of the surface of road pavement. Narita and Katsuragi (1978) showed that $L_{10}$ (10\% value from the top of accumulation distribution) of the vibration level (see Appendix) at the road side decreases by about $4 \mathrm{~dB}$ with the decrease of $1 \mathrm{~mm}$ of the standard deviation of the smoothness of the pavement surface determined by the $3 \mathrm{~m}$ long profile meter.

ii) Traffic flow control

Traffic flow control is also considered to be effective to reduce the traffic-induced ground vibrations. If the speed and weight of large cars were decreased by means of traffic control, the ground vibrations due to these cars would be reduced. Moreover it is confirmed that large trucks mainly cause ground vibrations and if large trucks were controlled to pass the center lane of the highway it would reduce the ground vibrations.

One of the authors Taniguchi (1980) showed on the basis of test data by using test trucks at five sites that the mean value of reduction of the vibration level (VL) by changing the moving lane from outside to inside is $2.2 \sim 3.6 \mathrm{~dB}$ for $\mathrm{VL}(1)=40 \sim 60 \mathrm{~dB}$ and that is $6.5 \sim$ $7.0 \mathrm{~dB}$ for $\mathrm{VL}(1)=60 \sim 70 \mathrm{~dB}$, where $\mathrm{VL}(1)$ means the vibration level at distances of 2.5 $\sim 5.0 \mathrm{~m}$ from the center of outside lane in the case of test truck moving in the outside lane. Furthermore controlling the moving lane of large trucks generates psycologically good effects to people living near highway. Therefore it is concluded that changing moving lane of large trucks is very effective to decrease the traffic-induced ground vibrations.

iii) Improving road structure

Increasing the rigidity of road pavement is considered to be valid to reduce the ground vibrations but this problem remains unsolved and further investigations are needed for 
understanding it quantitatively.

Constructing embankment type road is also effective to decrease the traffic-induced ground vibrations. Taniguchi, Sasaki and Tateyama (1980) derived the following relationship between the reduction of $L_{10}, \Delta L_{10}$, at toe of the road embankment by constructing embankment road and the cross area of the embankment $S$ on the basis of measurement data of actual traffic-induced vibrations at 53 sites in Japan.

$$
\Delta L_{10}=0.05 S
$$

One reason for this phenomenon is that the well compacted embankment has in general higher rigidity than subsoils and so the generated vibration on the embankment road is lower than on the flat road. The other reason is that the Rayleigh wave is dominant in traffic-induced vibrations and the propagation path of the Rayleigh wave in embankment road is longer than that in flat road and so the attenuation with distance becomes larger in embankment road.

iv) Construction of environmental zone

The environmental zone is a space between road and private land. The reduction of traffic-induced ground vibrations by the environmental zone is due to the attenuation with distance of vibrations. Suppose that an environmental zone with $20 \mathrm{~m}$ width is constructed and the outside edge of the traffic lane is at a distance of $5 \mathrm{~m}$ from the center of the outside lane, the reduction of the ground vibrations caused by this environmental zone can be calculated by using Table 1 (Taniguchi, 1980). It can be estimated that $L_{10}$ at the outside edge of environmental zone is lower by $5.0 \sim 11.6$ $\mathrm{dB}$ in sandy ground and lower by 2.6 $\sim 6.2 \mathrm{~dB}$ in clayey ground than $L_{10}$ at the inside edge of environmental zone. Therefore the environmental zone is very effective for the traffic-induced vibration control.

Table 1. Prediction table of attenuation of traffic-induced vibrations ${ }^{10)}$

\begin{tabular}{|c|c|c|c|}
\hline $\begin{array}{l}L_{10} \text { at reference } \\
\text { point* (dB) } \\
\begin{array}{l}\text { subsoil } \\
\text { condition }\end{array}\end{array}$ & $0<L_{10} \leqq 45$ & $45<L_{10} \leqq 55$ & $55<L_{10}$ \\
\hline clayey ground & $\begin{array}{l}1.3 \\
\{1.22\} \\
(92)\end{array}$ & $\begin{array}{l}2.0 \\
\{1.33\} \\
(238)\end{array}$ & $\begin{array}{l}3.1 \\
\{1.15\} \\
(85)\end{array}$ \\
\hline sandy ground & & $\begin{array}{l}2.5 \\
1.86\} \\
515)\end{array}$ & $\begin{array}{l}5.8 \\
\{4.18\} \\
(52)\end{array}$ \\
\hline
\end{tabular}

upper : reduction of $L_{10}(\mathrm{~dB})$ per double distance

\{\} : standard deviation (dB)

( ) : number of data

* Reference point is at a distance of $5 \mathrm{~m}$ from the center of the outside lane.

Actually a large space is required to construct the environmental zone and so it is necessary to make a synthetic land use plan in the case of choosing this method for an environmental countermeasure of new highway.

v) Improving soft ground

This paper mainly deals with this countermeasure. Traffic-induced vibrations of ten cause damage to people and buildings in soft ground and so the countermeasure for the vibration problems in soft ground are especially needed. It is reasonable to think that the improvement of soft ground can be a good countermeasure to this problem. Field experiments on the improvement of soft clayey ground by lime pile method were performed and its effectiveness to reduce the ground vibrations was examined. Moreover the finite element analyses were carried out to obtain information about the effects of the ground improvement on the decrease of ground vibrations. The detail will be described in following sections.

vi) Setting up isolating barrier or trench in the ground

Many investigations are reported (Richart et al., 1970 etc.) on the isolation of ground 
vibrations by a trench and Sawada and Taniguchi (1976) showed by model test that the acceleration at the ground surface comes down to $50 \%$ if a trench with a quarter depth of the wave length is set up in the propagation path of surface waves and it comes to $35 \%$ and $20 \%$ by a trench with half and full depth of the wave length respectively. It is thought that the reduction of ground vibrations by an isolating barrier of chemical sponge is a little smaller than that by a trench with nothing. However the wave length of the traffic-induced vibrations is in general $5 \sim 30 \mathrm{~m}$ and so a very deep isolating barrier is required to cut off the ground vibrations and its construction and maintenance is difficult.

\section{FIELD TEST ON THE REDUCTION OF GROUND VIBRATIONS BY IMPROVING SOFT GROUND}

\section{Purpose}

The purpose of the field test described here is i) to understand how much the ground vibrations can be decreased by improving soft clayey ground by lime pile method, and ii) to know the difference of reduction of ground vibrations due to the variation of improvement area of soft ground.

\section{Test Site}

The test site is located in Tottori city (West Japan) and the construction of new bypass is planned at the test site. The test site has low embankment with the height of $1 \mathrm{~m}$ on the very soft ground and any road structure was not yet constructed. The thickness of the soft layer of the ground is $13 \sim 15 \mathrm{~m}$. The surrounding place is used for paddy field and so the background vibration is very low.

\section{Method of Soft Ground Improvement}

The soft clayey ground at the test site was improved by lime pile method. In this method burnt lime $(\mathrm{CaO})$ is injected into the ground to form lime piles and burnt lime changes into slaked lime $\left(\mathrm{Ca}(\mathrm{OH})_{2}\right)$ by absorbing water in soils as expressed by the following equation.

$$
\mathrm{CaO}+\mathrm{H}_{2} \mathrm{O} \longrightarrow \mathrm{Ca}(\mathrm{OH})_{2}
$$

At this test site the diameter of lime pile is $0.4 \mathrm{~m}$, the length is $12 \mathrm{~m}$ and the pitch is $0.9 \mathrm{~m}$ and piles were arranged in rectangular form. The number of piles is 782 (34 columns and 23 lines) and the mass of burnt lime per pile is $1960 \mathrm{~kg}$.

The construction of lime piles was performed in two periods. At the first construction No. 1 area of about $300 \mathrm{~m}^{2}$ was improved as shown in Fig. 1 and after about 150 days No. 2 area of same size adjacent to No. 1 area was improved.

\section{Method of Investigations}

i) Survey of subsoils

Survey of subsoils was performed by boring, sampling of undisturbed samples, Dutch and Swedish cone sounding, $\mathrm{P}$ and $\mathrm{S}$ wave survey before and after improving soft ground. Tests on soil properties (density, water content, liquid limit, plastic limit, etc.), unconfined compression test, triaxial compression test (UU), consolidation test, and resonant column test were carried out by using undisturbed soil samples.

ii) Vibration tests

a) Source

The vibration generator shown in Fig. 2 was used in this series of tests. This vibration generator causes vibrations by rotating unbalanced mass and the vibrations are transmitted 


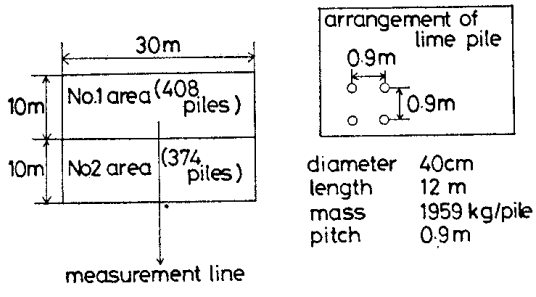

Fig. 1. Improved area

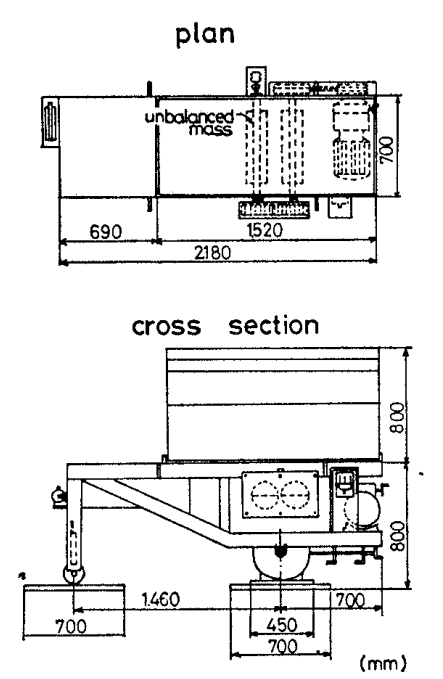

Fig. 2. Vibration generator

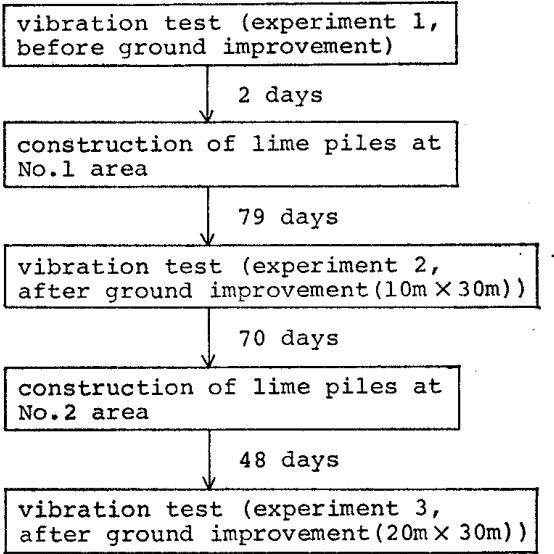

Fig. 3. Flow chart of investigations
Table 2. Test conditions

\begin{tabular}{|c|c|}
\hline applied force $(\mathrm{kN})$ & frequency $(\mathrm{Hz})$ \\
\hline \multirow{4}{*}{4.90} & 6.9 \\
\hline & 9.9 \\
\hline & 13.3 \\
\hline & 17.8 \\
\hline \multirow{3}{*}{7.84} & 8.6 \\
\hline & 12.2 \\
\hline & 16.0 \\
\hline 6.37 & 19.8 \\
\hline
\end{tabular}

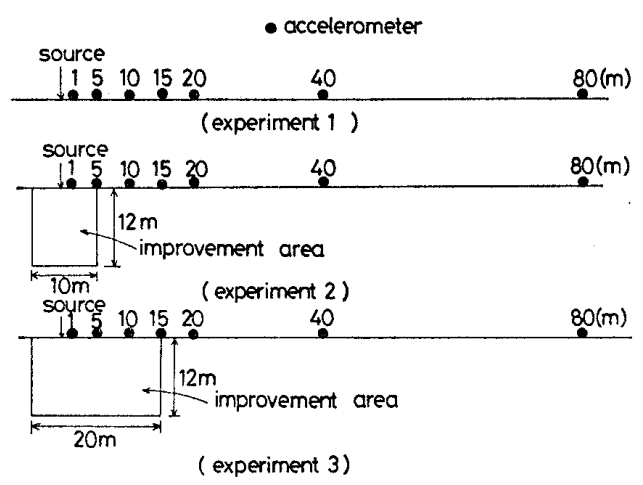

Fig. 4. Measurement points

through two iron wheels to the ground.

b) Measurement equipment

The ground vibration was measured by servo type accelerometers on the ground surface. All data were recorded by an analogue data recorder.

c) Test condition

The test condition is shown in Table 2. The magnitude of applied force and frequency were controlled by changing the rotation cycles of the vibration generator and the weight of unbalanced mass.

d) Test case and measurement points

The vibration tests were performed for three times as shown in Fig. 3; before the ground improvement, after the improvement at No.1 area and after the improvement at No. 2 area. Fig. 4 shows the location of the vibration genearator and the receivers of accelerometers, which were set up at distances of $1,5,10,15,20,40$, and $80 \mathrm{~m}$ from the source. The three components of acceleration were measured.

\section{Results and Discussions}

i) Subsoils

Fig. 5 shows the cross section of the ground along the vibration measurement line. This figure shows that this site has almost horizontal layers and the ground as deep as $12 \mathrm{~m}$ from the surface has so soft clayey soil that Swedish sounding cone sinks with the mass of $100 \mathrm{~kg}$. 


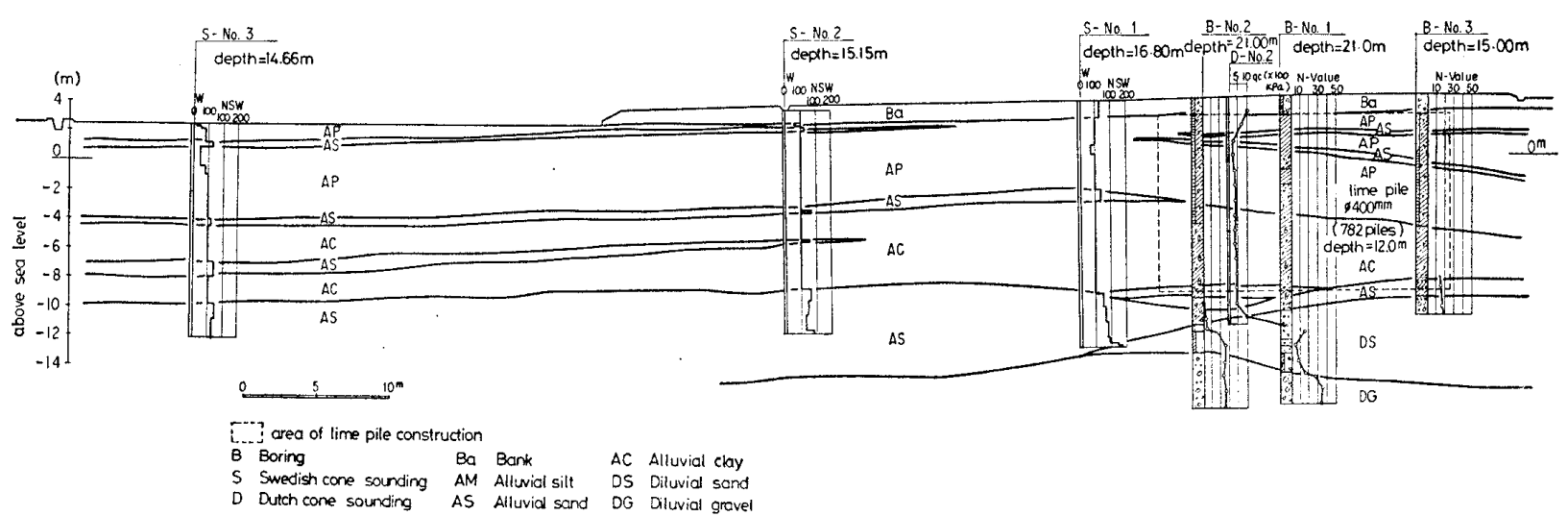

Fig. 5. Geological cross section of the ground along the measurement line

Table 3. Change of soil properties due to soft ground improvement by lime pile method

\begin{tabular}{|c|c|c|c|c|c|c|c|c|c|c|c|c|}
\hline \multirow{2}{*}{$\begin{array}{l}\text { depth } \\
\text { (m) }\end{array}$} & \multicolumn{3}{|c|}{ water content $(\%)$} & \multicolumn{3}{|c|}{ wet density $\left(\mathrm{g} / \mathrm{cm}^{3}\right)$} & \multicolumn{3}{|c|}{ void ratio } & \multicolumn{3}{|c|}{ dry density $\left(\mathrm{g} / \mathrm{cm}^{3}\right)$} \\
\hline & B & A & $\mathrm{A} / \mathrm{B}(\%)$ & B & A & $\mathrm{A} / \mathrm{B}(\%)$ & B & A & $\mathrm{A} / \mathrm{B}(\%)$ & $\mathrm{B}$ & A & $\mathrm{A} / \mathrm{B}(\%)$ \\
\hline $3.1 \sim 3.9$ & 94.0 & 64.3 & 68.4 & 1.43 & 1.56 & 108.7 & 2.27 & 1.55 & 68.5 & 0.739 & 0.949 & 128.4 \\
\hline $5.0 \sim 5.8$ & 136.0 & 78.8 & 57.9 & 1.34 & 1.52 & 114.0 & 3.39 & 1.97 & 58.0 & 0.566 & 0.851 & 150.4 \\
\hline $6.0 \sim 6.8$ & 104.1 & 74.5 & 71.6 & 1.36 & 1.50 & 110.2 & 2.72 & 1.90 & 70.0 & 0.665 & 0.857 & 128.9 \\
\hline $8.5 \sim 9.3$ & 104.4 & 77.5 & 74.2 & 1,41 & 1.50 & 105.8 & 2.66 & 2.01 & 75.4 & 0.691 & 0.842 & 121.9 \\
\hline $9.5 \sim 10.3$ & 80.0 & 56.2 & 70.3 & 1.46 & 1.63 & 111.8 & 2.16 & 1.45 & 67.2 & 0.812 & 1.046 & 128.8 \\
\hline $12.2 \sim 12.5$ & 88.6 & 48.1 & 54.3 & 1. 48 & 1.71 & 116.1 & 2.28 & 1.25 & 55.0 & 0.782 & 1.157 & 148.0 \\
\hline \multirow{2}{*}{$\begin{array}{l}\text { depth } \\
(\mathrm{m})\end{array}$} & \multicolumn{3}{|c|}{ liquid limit (\%) } & \multicolumn{3}{|c|}{ plastic limit $(\%)$} & \multicolumn{3}{|c|}{ plasticity index } & \multicolumn{3}{|c|}{$\begin{array}{l}\text { unconfined compressive } \\
\text { strength }(\mathrm{kPa})\end{array}$} \\
\hline & B & A & $\mathrm{A} / \mathrm{B}(\%)$ & B & $A$ & $|\mathrm{~A} / \mathrm{B}(\%)|$ & $\mathbf{B}$ & A & $\mathrm{A} / \mathrm{B}(\%)$ & B & A & $\mathrm{A} / \mathrm{B}(\%)$ \\
\hline $3.1 \sim 3.9$ & 109.2 & 86.7 & 79.4 & 77.7 & 41.9 & 53.9 & 31.5 & 44.8 & 142.2 & 40.8 & 65.8 & 161.3 \\
\hline $5.0 \sim 5.8$ & 146.2 & 94.5 & 64.6 & 72.0 & 42.2 & 58.6 & 74.3 & 52.4 & 70.5 & 41.1 & 56.4 & 137.5 \\
\hline $6.0 \sim 6.8$ & 107.3 & 104.3 & 97.2 & 54.3 & 49.4 & 91.0 & 53.0 & 54.9 & 103.5 & 40.6 & 84.3 & 208.0 \\
\hline $8.5 \sim 9.3$ & 103.6 & 94.3 & 91.0 & 48.3 & 48.4 & 100.3 & 55.3 & 45.9 & 82.9 & 33.3 & 94.8 & 284.4 \\
\hline $9.5 \sim 10.3$ & 86.2 & 67.2 & 77.9 & 39.1 & 40.7 & 104.1 & 47.1 & 26.5 & 56.2 & 34.0 & 106.4 & 313.0 \\
\hline $12.2 \sim 12.5$ & 87.9 & 76.6 & 87.2 & 34.2 & 37.3 & 108.9 & 53.7 & 39.4 & 73.3 & 37.0 & 126.5 & 341.5 \\
\hline \multirow{2}{*}{$\begin{array}{l}\text { depth } \\
(\mathrm{m})\end{array}$} & \multicolumn{3}{|c|}{$\begin{array}{l}\text { angle of shearing } \\
\text { resistance (degree) }\end{array}$} & \multicolumn{3}{|c|}{ cohesion (kPa) } & \multicolumn{3}{|c|}{$\begin{array}{l}\text { coefficient of consoli- } \\
\text { dation }\left(\mathrm{cm}^{2} / \mathrm{min}\right)\end{array}$} & \multicolumn{3}{|c|}{$\begin{array}{l}\text { coefficient of permeability } \\
\times 10^{-7}(\mathrm{~cm} / \mathrm{s})\end{array}$} \\
\hline & B & A & $\mathrm{A} / \mathrm{B}(\%)$ & B & A & $\mid \mathrm{A} / \mathrm{B}(\%)$ & B & A & $\mid \mathrm{A} / \mathrm{B}(\%)$ & B & A & $\mathrm{A} / \mathrm{B}(\%)$ \\
\hline $3.1 \sim 3.9$ & 2.60 & 2.10 & 80.0 & 17.6 & 29.4 & 166.7 & - & - & - & - & - & - \\
\hline $5.0 \sim 5.8$ & - & - & - & - & - & - & 0.034 & 0.049 & 144.1 & 1.10 & 0.60 & 54.5 \\
\hline $6.0 \sim 6.8$ & 2.60 & 2.40 & 92.3 & 23.5 & 43.1 & 188. 3 & - & - & - & - & - & - \\
\hline $8.5 \sim 9.3$ & - & - & - & - & - & - & 0.031 & 0.042 & 135.5 & 1.81 & 0.42 & 23.2 \\
\hline $9.5 \sim 10.3$ & 2.90 & 2.80 & 96.6 & 20.6 & 53.9 & 261.9 & - & - & - & - & - & - \\
\hline $12.2 \sim 12.5$ & 4.00 & - & - & 13.7 & - & - & - & - & - & - & - & - \\
\hline
\end{tabular}

$B$ : before improving soft ground

A : after improving soft ground

Table 3 shows the comparison of soil properties. Water content was reduced to $54 \sim$ $74 \%$ and dry density was increased by $22 \sim 50 \%$ and unconfined compressive strength was also increased to $161 \sim 342 \%$ by soft ground improvement. Fig. 6 illustrates the P and S wave velocity and it can be noted that the $S$ wave velocity is increased by $1.8 \sim 3.7$ times by the ground improvement and the shear modulus calculated from $\mathrm{S}$ wave velocity is increased by 3.5 6.6 times. From these figures and tables it can be concluded that the soft ground was considerably solidified by the lime pile construction and the strength and deformation characteristics of the soil were improved.

ii) Reduction of ground vibrations by the ground improvement

Figs. 7 show the comparison of acceleration on the ground surface at various distances 


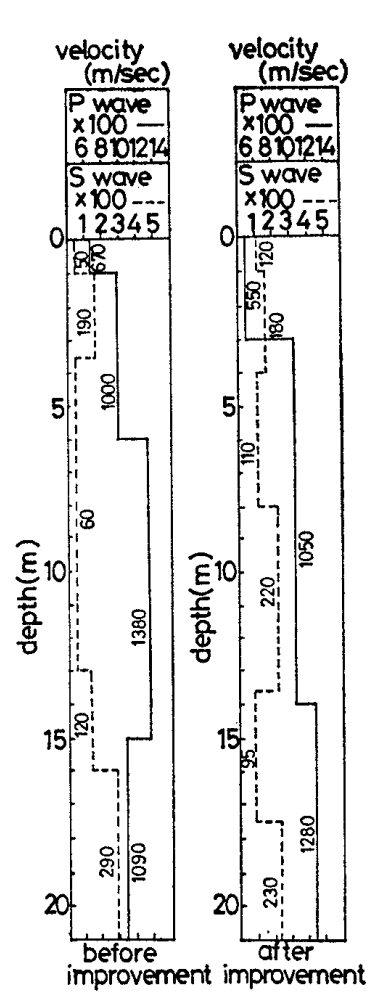

Fig. 6. Change of $\mathbf{P}$ and $\mathbf{S}$ wave velocity by ground improvement at No. 2 area

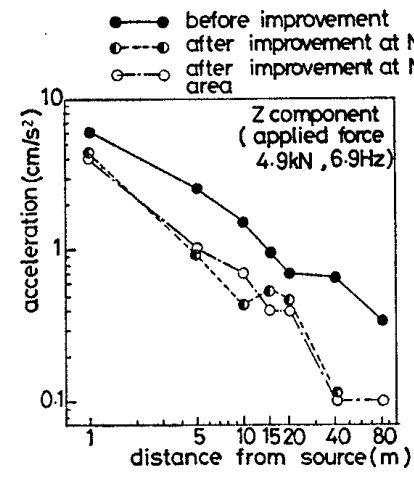

(a)

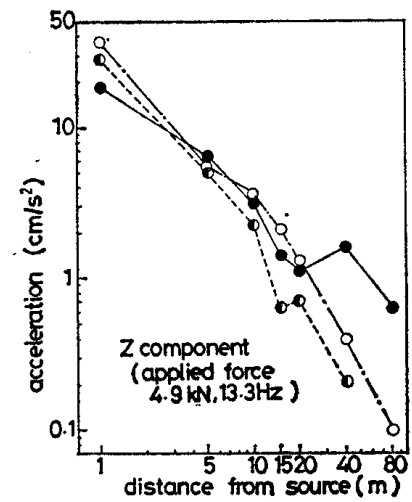

(c)

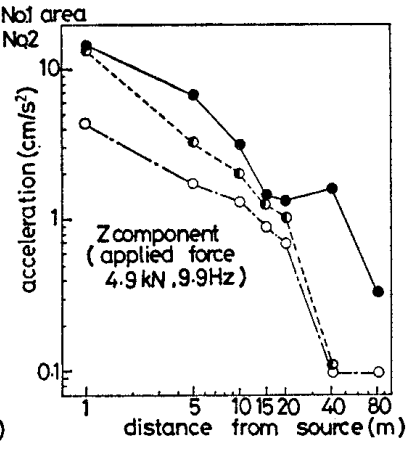

(b)

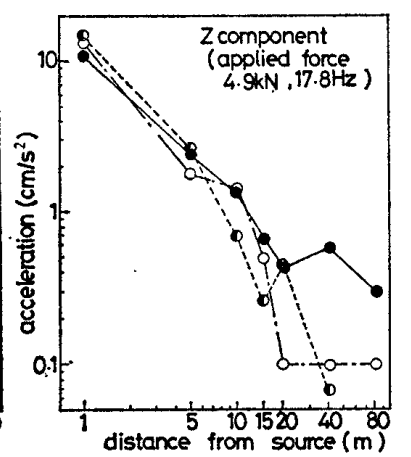

(d)
Fig. 7. Comparison of acceleration at ground surface before and after improvement (vertical component)

from the source before and after the ground improvement. In Fig. 7 the acceleration is fairly reduced in the case that the frequency is as low as $6.9 \sim 9.9 \mathrm{~Hz}$ but the reduction of acceleration is not clearly observed for the higher frequency range. The acceleration is reduced to $15 \sim 60 \%$ of that prior to the ground improvement for the frequency of $6.9 \mathrm{~Hz}$ (applied force $=4.9 \mathrm{kN}$ ) and it becomes $10 \sim 50 \%$ for the frequency of $8.6 \mathrm{~Hz}$ (applied force $=7.84 \mathrm{kN}$ ). The reason of this phenomenon is to be estimated as follows. The Rayleigh wave is dominant in the ground vibrations generated by being loaded on the ground surface and the lower the frequency, the deeper part of the ground is vibrated during the Rayleigh wave propagates (Richart et al., 1970). On the other hand Fig. 6 indicates that the shear wave velocity of the layer shallower than $4 \mathrm{~m}$ is almost same at both surveys before and after improvement and in the deeper part of the ground such as $4 \sim 13 \mathrm{~m}$ the shear wave velocity increases to $180 \sim 370 \%$ of that prior to the improvement. This can be a cause that the vibration with lower frequency was relatively decreased by the soft ground improvement in this test site.

On the relationship between the magnitude of vibration and the rigidity of the ground Lamb (1904) presented a theoretical solution. When a sinusoidally fluctuating point load $R e^{i \omega t}$ ( $R=$ amplitude of applied force, $i=\sqrt{-1}, \omega=$ circular frequency, $t=$ time) is vertically applied on the surface of elastic half space, the Rayleigh wave is dominant and its amplitude of the displacement at the distance $r$ from the source is expressed by

(horizontal)

$$
u=-\frac{i a R}{2 G} H \sqrt{\frac{2}{\pi a r}} \exp \left\{i\left(\omega t-a r-\frac{\pi}{4}\right)\right\}
$$


(vertical)

where

$$
v=\frac{a R}{2 G} K \sqrt{\frac{2}{\pi a r}} \exp \left\{i\left(\omega t-a r-\frac{\pi}{4}\right)\right\}
$$

$a=\frac{\omega}{V_{R}}, V_{R}$ : propagation velocity of the Rayleigh wave

$G$ : shear modulus

$H=\frac{k^{2}\left(2 a^{2}-k^{2}\right)^{3}}{-a F^{\prime}(a) f(a)}, \quad K=\frac{2 k^{2} \alpha_{1}\left(2 a^{2}-k^{2}\right)^{2}}{-F^{\prime}(a) f(a)}$

$f(a)=8 \alpha_{1} \beta_{1} a^{2}, \quad \alpha_{1}=\sqrt{a^{2}-h^{2}}, \quad \beta_{1}=\sqrt{a^{2}-k^{2}}$

$h=\frac{\omega}{V_{P}}, \quad k=\frac{\omega}{V_{S}}, V_{P}, V_{S}$ : propagation velocity of $\mathrm{P}$ and $\mathrm{S}$ wave respectively

$F(\xi)=\left(2 \xi^{2}-k^{2}\right)^{2}-4 \xi^{2} \alpha \beta$

$\alpha=\sqrt{\xi^{2}-h^{2}}, \quad \beta=\sqrt{\xi^{2}-k^{2}}$.

In Eqs. (3) and (4), if it is assumed that $V_{R}$ equals $m V_{S}\left(m=\right.$ constant) and $1 / V_{P}{ }^{2}$ can be neglected as compared with $1 / V_{S}{ }^{2}, u$ and $v$ are in proportion to $1 / V_{S}{ }^{2.5}$, because $H$ and $K$ in Eqs. (3) and (4) are independent of $V_{S}$ and $u$ (or $\left.v\right) \propto \frac{\sqrt{a}}{G}=\sqrt{\frac{\omega}{m V_{S}}} \frac{1}{\rho} V_{S^{2}}=\sqrt{\frac{\omega}{m}} \frac{1}{\rho} V_{S}^{-2.5}$. In the test site the value of $V_{S}$ is increased by 1.8 times at depths of $5 \sim 8 \mathrm{~m}$ and also increased by 3.7 times at depths of $8 \sim 13 \mathrm{~m}$ and this resulted in the decrease of ground vibrations. If the elastic half space is improved and $V_{S}$ is increased by 1.8 times, and the frequency of the vibration is constant before and after the improvement, it can be calculated from Eqs. (3) and (4) that the acceleration (or displacement) of the ground will decrease to $1 / 1.8^{2.5}(=23 \%)$. Although the actual ground at Tottori was not uniformly improved and the region of the improvement was limited, the measured reduction of the ground vibration for the frequency range less than $10 \mathrm{~Hz}$ is in same order as estimated by Eqs. (3) and (4).

Figs. 7 indicate that the acceleration scarcely changed when the width of the improved ground area was increased from $10 \mathrm{~m}$ to $20 \mathrm{~m}$. This result gives an advantageous information to take a countermeasure to traffic-induced vibrations, because it implies that the improvement of only the ground just under the road is enough to reduce the ground vibration, considering that the width of two lane road in general is about $10 \mathrm{~m}$.

iii) Predominant frequency

The ground vibration caused by actual traffic was measured at a distance of $8 \mathrm{~m}$ from the center of the outside lane of the national highway route 9 located at about $300 \mathrm{~m}$ away from the test site described above. Fig. 8 shows the result of frequency analysis by using $1 / 3$ octave

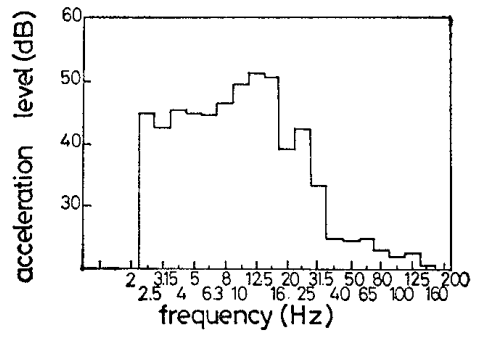

Fig. 8. Results of frequency analysis (at road side of route 9 about $300 \mathrm{~m}$ away from the test site)

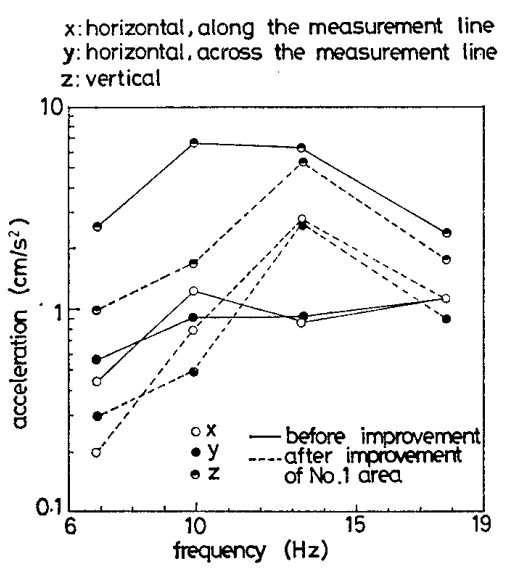

Fig. 9. Relationship between acceleration and frequency

band frequency analyzer. This figure indicates that the maximum peak of acceleration 
level (see Appendix) is at $12.5 \mathrm{~Hz}$ and lower frequency is dominant. Therefore considering the test results put forth in the preceeding section that the reduction of the ground vibration is observed in the lower frequency range than $10 \mathrm{~Hz}$, it is reasonable to think that the construction of lime piles with $12 \mathrm{~m}$ depth is effective to decrease the traffic-induced ground vibration at this area.

Fig. 9 shows the relationship between acceleration and frequency before and after ground improvement of No. 1 area. In this figure the maximum acceleration appears at frequency of $9.9 \mathrm{~Hz}$ before ground improvement and it appears at frequency of $13.3 \mathrm{~Hz}$ after improvement. Although the number of data is too small to obtain a full resonant curve, it can be noted from Fig. 9 that the predominant frequency of the ground is slightly increased by the ground improvement.

\section{FINITE ELEMENT ANALYSES}

\section{Purpose}

The purpose of the finite element analyses performed here is i) to confirm that the finite element technique used here is useful to treat the surface wave propagation problem, and ii) to develop a prediction method of the reduction of traffic-induced ground vibrations by improving the soft ground.

\section{Computer Program}

The computer program designated "LUSH" was used in the calculation. This program was developed by Lysmer et al. (1974) at University of California, Berkeley for analyzing the dynamic response of the ground or structures to the earthquake loading and other dynamic loading by the two dimensional finite element method. This program is based on the equivalent linear method and the method of complex response. The nonlinearity of the stress-strain relationship of soils can be taken in to account by considering the strain dependent characteristics of the shear modulus and damping ratio. But in this series of calculation the shear modulus and damping ratio of soils were assumed independent of shear strain. The response of the model is calculated in the frequency domain.

\section{Computer}

The computer used in this calculation is HITAC M-180 installed in the Public Works Research Institute.

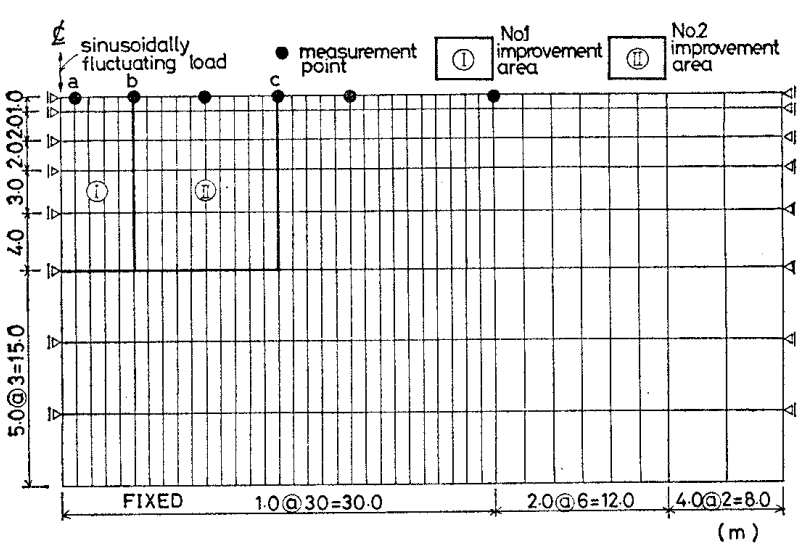

(a) Model A

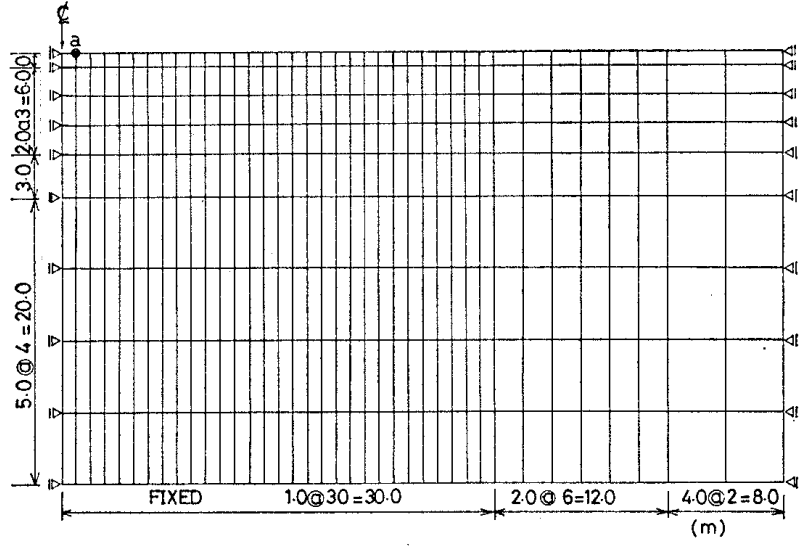

(b) Model B

Fig. 10. Models used in the analyses 


\section{Models}

Two models shown in Figs. 10 were used in the analyses. The ground at Tottori described in the previous section is simulated in the model A. The model B represents the typical soft ground and it was used to develop a prediction method of the decrease of ground vibrations by soft ground improvement. In both models the boundary conditions are; fixed at bottom and vertically free and horizontally fixed at both sides. To eliminate the effects of the reflection of waves at the boundary as much as possible, the damping ratio of the most outside elements was taken as $10 \%$, while that of other elements is $2 \sim 7 \%$. The size of finite elements was determined to satisfy the condition that the width of the element is less than one fifth of the wave length.

Both the model and loading condition of the analyses conducted here are symmetric and so the half model was used to shorten the computation time. The soil properties of the ground for model A are shown in Fig.11. The shear wave velocity was measured by the $\mathrm{P}$ and $\mathrm{S}$ wave survey at the field site. The damping ratio of the ground was taken as $7 \%$ from the resonant column test results by using undisturbed soil samples (Taniguchi, Ogasawara and Sawada, 1978). The damping ratio of the improved ground was not actually measured and so it was assumed equal to the damping ratio of the unimproved ground. The soil properties of model B were taken as parameters.

\section{Method of Analyses}

A sinusoidally fluctuating force was applied at the left edge of surface of the half model as shown in Figs. 10. The configuration of the applied force is illustrated in Fig. 12. The quiet zone with 1.56 times period as long as sinusoidal waves follows the sinusoidal waves. The quiet zone is needed to obtain correct Fourier transformation in the computer program used here. The time interval of the input data $\Delta T$ was taken as one twentieth of the period of sinusoidal wave.

The analyses are composed of two parts as follows.

(analysis 1)

In the analysis 1 the results of calculation by the finite element method is compared with those of field measurement at Tottori. The calculation is performed in three cases;

i) the ground is not improved

ii) No. 1 area is improved

iii) No. 1 and No. 2 area is improved.

The frequency of applied force is $6.9 \mathrm{~Hz}$ and the amplitude is $2.45 \mathrm{kN}(=4.9 / 2 \mathrm{kN}, 250$ kgf).
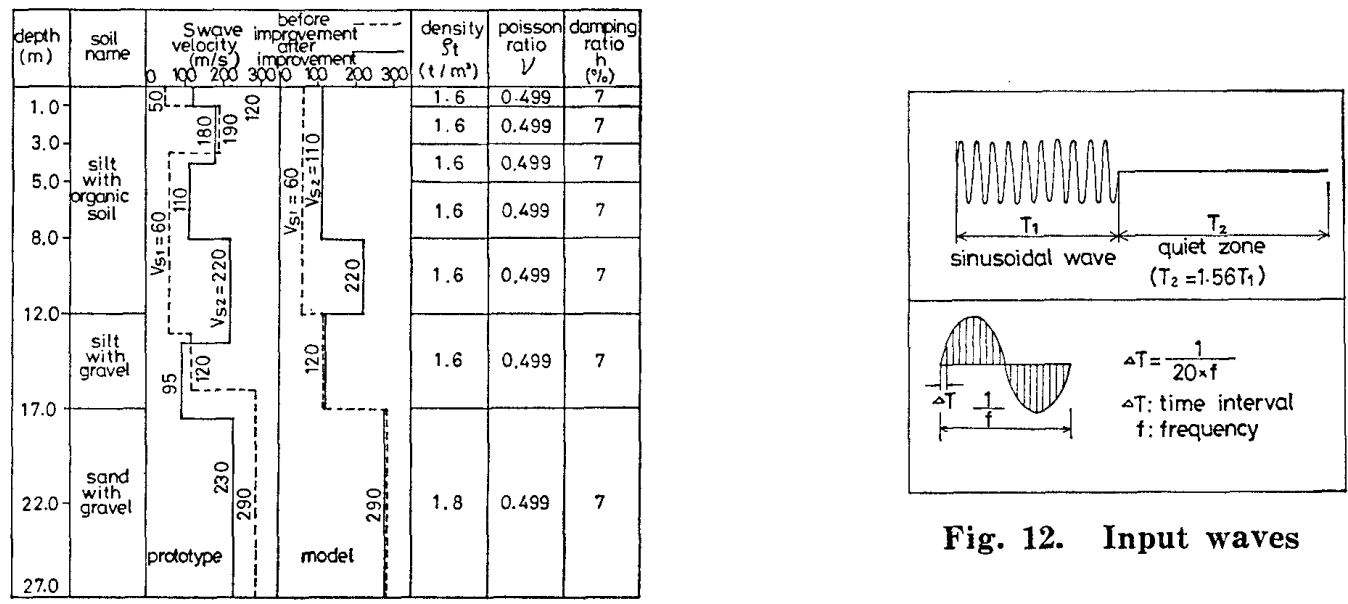

Fig. 12. Input waves

Fig. 11. Soil properties for Model A 
Table 4. Calculation conditions (analysis 2)

\begin{tabular}{|c|c|c|c|c|c|c|c|}
\hline No. & $\begin{array}{l}\text { S wave velocity } \\
\text { of unimproved } \\
\text { ground } \mathrm{v}_{\mathrm{SI}} \text { (m/sec) }\end{array}$ & $\begin{array}{l}\text { s wave velocity } \\
\text { of improved } \\
\text { ground } \mathrm{V}_{\mathrm{S2}}(\mathrm{m} / \mathrm{sec})\end{array}$ & $\begin{array}{l}\text { frequency } \\
(\mathrm{Hz})\end{array}$ & $\begin{array}{l}\text { depth of } \\
\text { improvement } \\
\text { (m) }\end{array}$ & $\begin{array}{l}\text { model } \\
\text { No. }\end{array}$ & $\begin{array}{l}\text { damping } \\
\text { ratio } \\
(8)\end{array}$ & model \\
\hline $\begin{array}{l}1 \\
2 \\
3 \\
4 \\
\end{array}$ & $\begin{array}{l}100 \\
100 \\
100 \\
150 \\
\end{array}$ & $\begin{array}{l}100 \\
100 \\
100 \\
150 \\
\end{array}$ & $\begin{array}{r}5 \\
10 \\
20 \\
10 \\
\end{array}$ & $\begin{array}{l}0 \\
0 \\
0 \\
0 \\
\end{array}$ & $\begin{array}{l}\mathrm{B} \\
\mathrm{B} \\
\mathrm{B} \\
\mathrm{B} \\
\end{array}$ & $\begin{array}{r}2 \\
2 \\
2 \\
2 \\
2 \\
\end{array}$ & (1) \\
\hline $\begin{array}{r}5 \\
6 \\
7 \\
8 \\
9 \\
10 \\
11 \\
12 \\
13 \\
14 \\
15 \\
\end{array}$ & $\begin{array}{l}100 \\
100 \\
100 \\
100 \\
100 \\
100 \\
100 \\
100 \\
150 \\
150 \\
150 \\
\end{array}$ & $\begin{array}{l}150 \\
150 \\
300 \\
500 \\
200 \\
200 \\
200 \\
200 \\
225 \\
300 \\
450 \\
\end{array}$ & $\begin{array}{r}10 \\
10 \\
10 \\
10 \\
10 \\
10 \\
5 \\
20 \\
10 \\
10 \\
10 \\
\end{array}$ & $\begin{array}{l}3 \\
3 \\
3 \\
3 \\
3 \\
3 \\
3 \\
3 \\
3 \\
3 \\
3 \\
\end{array}$ & $\begin{array}{l}\mathrm{B} \\
\mathrm{B} \\
\mathrm{B} \\
\mathrm{B} \\
\mathrm{B} \\
\mathrm{B} \\
\mathrm{B} \\
\mathrm{B} \\
\mathrm{B} \\
\mathrm{B} \\
\mathrm{B} \\
\end{array}$ & $\begin{array}{r}2 \\
2 \\
2 \\
2 \\
5 \\
10 \\
2 \\
2 \\
2 \\
2 \\
2 \\
\end{array}$ & (2) \\
\hline $\begin{array}{l}16 \\
17 \\
18 \\
\end{array}$ & $\begin{array}{l}100 \\
100 \\
100 \\
\end{array}$ & $\begin{array}{l}200 \\
200 \\
200 \\
\end{array}$ & $\begin{array}{r}5 \\
10 \\
20 \\
\end{array}$ & $\begin{array}{l}5 \\
5 \\
5 \\
\end{array}$ & $\begin{array}{l}\mathrm{B} \\
\mathrm{B} \\
\mathrm{B} \\
\end{array}$ & $\begin{array}{l}2 \\
2 \\
2 \\
\end{array}$ & (3) \\
\hline $\begin{array}{l}19 \\
20 \\
21 \\
22 \\
23 \\
24 \\
25 \\
26 \\
27 \\
28 \\
29 \\
\end{array}$ & $\begin{array}{l}100 \\
100 \\
100 \\
100 \\
100 \\
100 \\
100 \\
100 \\
150 \\
150 \\
150 \\
\end{array}$ & $\begin{array}{l}150 \\
200 \\
300 \\
500 \\
200 \\
200 \\
200 \\
200 \\
225 \\
300 \\
450 \\
\end{array}$ & $\begin{array}{r}10 \\
10 \\
10 \\
10 \\
10 \\
10 \\
5 \\
20 \\
10 \\
10 \\
10 \\
\end{array}$ & $\begin{array}{l}10 \\
10 \\
10 \\
10 \\
10 \\
10 \\
10 \\
10 \\
10 \\
10 \\
10 \\
\end{array}$ & $\begin{array}{l}\text { B } \\
\text { B } \\
\text { B } \\
B \\
\text { B } \\
\text { B } \\
\text { B } \\
\text { B } \\
B \\
B \\
B \\
\end{array}$ & $\begin{array}{r}2 \\
2 \\
2 \\
2 \\
5 \\
10 \\
2 \\
2 \\
2 \\
2 \\
2 \\
\end{array}$ & (4) \\
\hline 30 & 100 & 200 & 10 & 15 & B & 2 & (5) \\
\hline $\begin{array}{l}31 \\
32 \\
33 \\
34\end{array}$ & $\begin{array}{l}100 \\
100 \\
100 \\
100\end{array}$ & $\begin{array}{l}150 \\
200 \\
300 \\
200\end{array}$ & $\begin{array}{r}10 \\
10 \\
10 \\
5 \\
\end{array}$ & $\begin{array}{l}20 \\
20 \\
20 \\
20 \\
\end{array}$ & $\begin{array}{l}\mathrm{B} \\
\mathrm{B} \\
\mathrm{B} \\
\mathrm{B}\end{array}$ & $\begin{array}{l}2 \\
2 \\
2 \\
2 \\
\end{array}$ & (6) \\
\hline
\end{tabular}
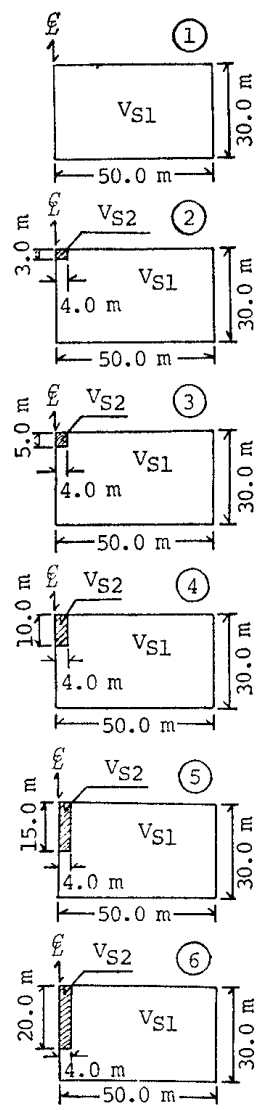

(analysis 2)

The purpose of the analysis 2 is to develop a prediction method of the reduction of ground vibrations by soft ground improvement.

Several parameters were taken in the calculation such as the shear wave velocity of the unimproved and improved ground, the frequency of applied force, the depth of improvement area. The damping ratio of the ground was assumed $2 \%$. The effects of the variation of damping ratio was also examined by changing damping ratio from $2 \%$ to $10 \%$. Table 4 shows the case of calculation.

\section{Results and Discussions}

Figs. 13 show the comparison of the measured and calculated values of acceleration at various distances from the source on the ground surface. In these figures the values of acceleration are normalized by dividing by $A_{0}(=$ calculated acceleration amplitude at a distance of $1 \mathrm{~m}$ from the source) and the ratios $A / A_{0}$ ( $A$ : acceleration at any point) of calculation and measurement are taken equal at a distance of $5 \mathrm{~m}$ from the source. The calculated values are modified by multiplying $1 / \sqrt{r}(r$ : distance from the source) which corresponds to the geometrical damping of the Rayleigh wave, to take in to account the three dimensional damping effect.

Figs. 13 indicate that the calculated accelerations agree very well with measured values in both cases of unimproved and improved grounds and that the analysis conducted here has good accuracy from engineering point of view to evaluate the acceleration on the ground surface generated by a point source.

Fig. 14 and Fig. 15 show the results of calculation and field measurement on the reduction of ground vibrations by improving soft ground. The results of finite element calculation 


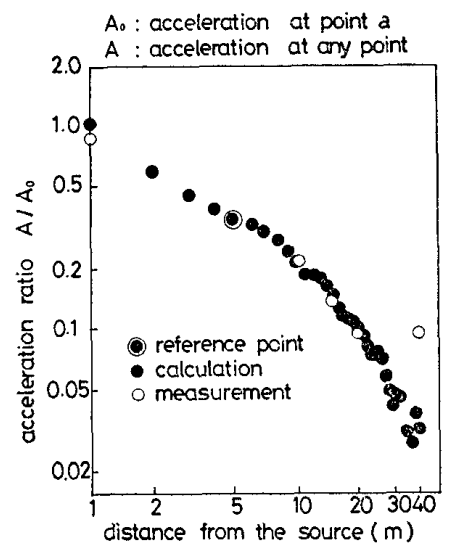

(a) before improvement

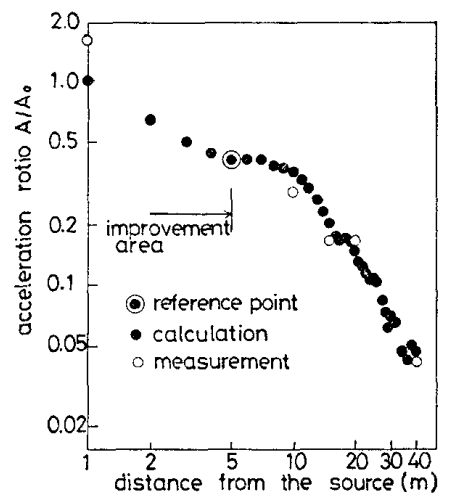

(b) after improvement of No. 1 area

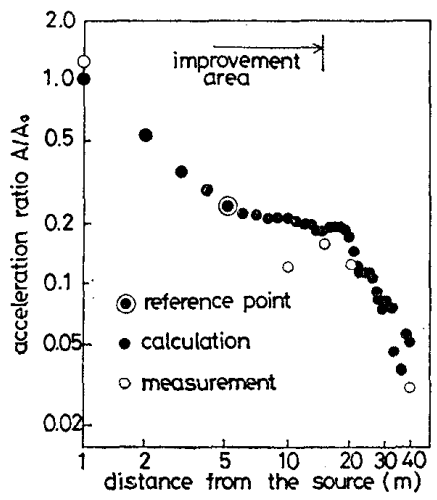

(c) after improvement of No. 1 and No. 2 area

Fig. 13. Comparison of calculated acceleration with measured acceleration

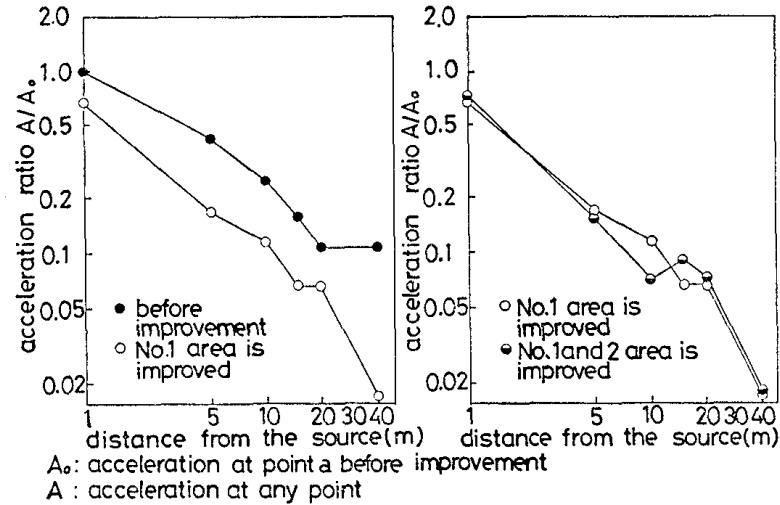

Fig. 14. Change of acceleration by ground improvement (measurement)
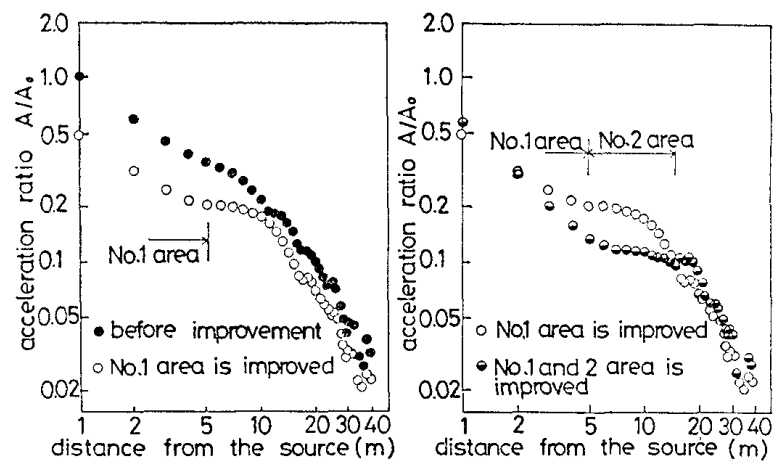

Fig. 15. Change of acceleration by ground improvement (calculation)

indicate that the ground vibration is reduced by $20 \sim 50 \%$ by improving No. 1 area and the reduction of acceleration by improving No. 1 and No. 2 area is almost same as that by improving No. 1 area except at the range from $5 \mathrm{~m}$ to $15 \mathrm{~m}$. These results are similar to those of the field tests.

Figs. 16 show the attenuation with distance of calculated acceleration in the analysis 2 and these calculated values were approximated by

$$
A=A_{1}\left(\frac{r_{1}}{r}\right)^{n} \exp \left\{-\alpha\left(r-r_{1}\right)\right\}
$$

where $A, A_{1}=$ acceleration at distances of $r$ and $r_{1}$ from the source respectively, $n=$ constant of geometrical damping, $\alpha=$ attenuation coefficient. The attenuation coefficient $\alpha$ was determined in the condition that the distance of the reference point from the source $r_{1}$ in Eq. (5) was taken as $1 \mathrm{~m}$. The acceleration given by Eq. (5) with above determined $\alpha$ is to be used to develop a prediction figure in the following analysis.

Fig. 17 shows the prediction figure of the reduction of acceleration at a distance of $5 \mathrm{~m}$ from the source by improving soft ground in terms of the depth of improvement and the ratio of shear wave velocity $V_{S 2} / V_{S 1}\left(V_{S 1}\right.$ and $V_{S 2}$ are the shear wave velocity of before and after ground improvement respectively.). The vertical axis of Fig. 17 is expressed by the reduction of vibration level instead of acceleration to be easily used for traffic-induced vibrations. The condition of the calculation is that the width of 


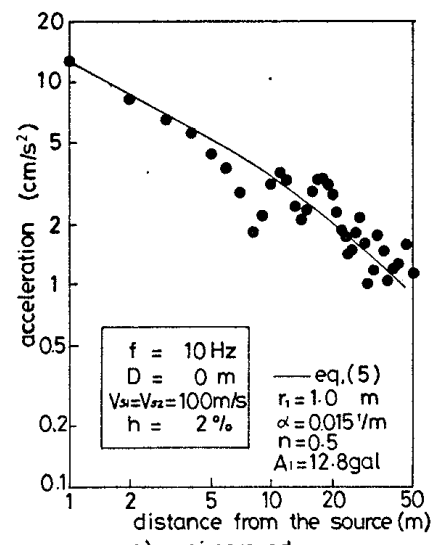

a) unimproved

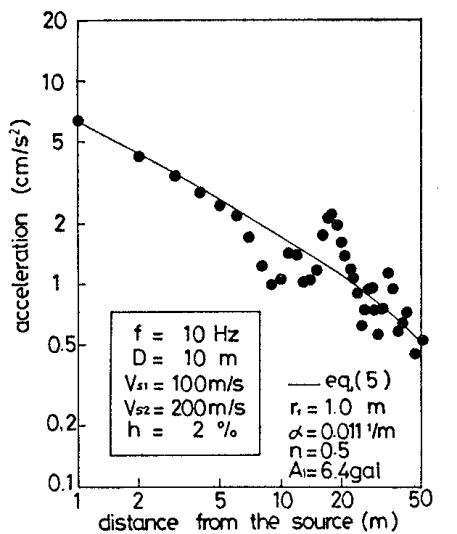

b) improved(depth of improvement

Fig. 16. Attenuation with distance of calculated acceleration

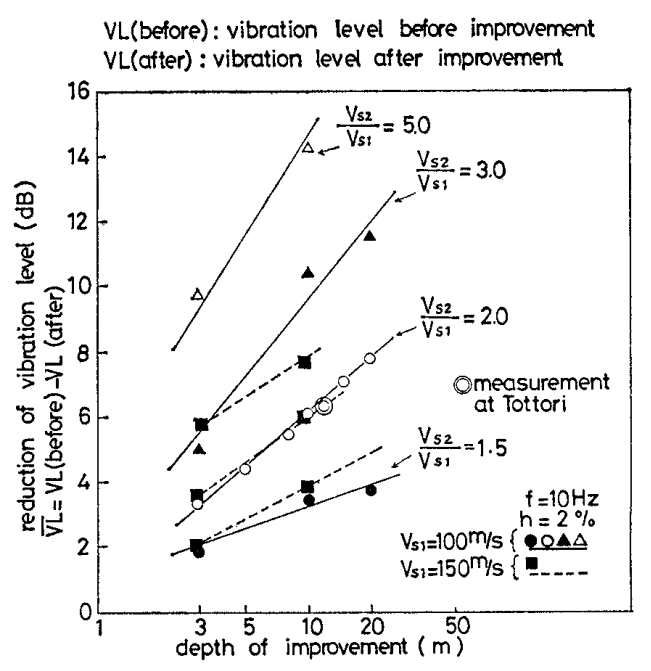

Fig. 17. Prediction figure of reduction of ground vibrations by soft ground improvement

improvement is $8 \mathrm{~m}$ and the frequency of the applied force is $10 \mathrm{~Hz}$, the damping ratio is $2 \%$ and the shear wave velocity of the unimproved ground is $100 \mathrm{~m} / \mathrm{s}$ and $150 \mathrm{~m} / \mathrm{s}$. These values corresponds to the traffic-induced vibrations in a typical soft ground in Japan.

Fig. 17 indicates that the reduction of ground vibrations increases with the increase of the depth of improvement and $V_{S 2} / V_{S 1}$. The relationship between the reduction of vibration level and logarithm of the depth of ground improvement can be approximated by a straight line in the region of $3 \sim 20 \mathrm{~m}$. In Fig. 17 the experimental value at Tottori is also shown and it well agrees with calculation.

In comparison of the reduction of vibration level in the case of $V_{S 1}=100 \mathrm{~m} / \mathrm{s}$ and $V_{S 1}=$

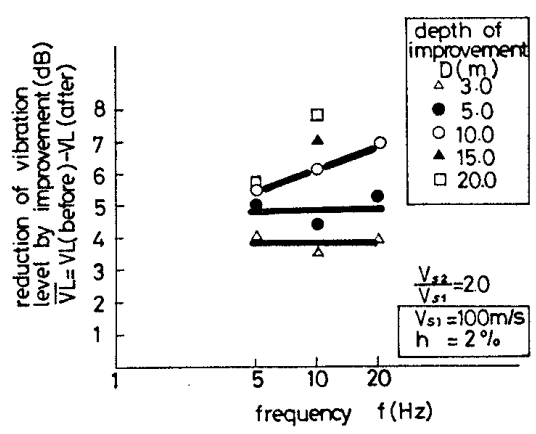

Fig. 18. Effects of frequency on the reduction of ground vibrations

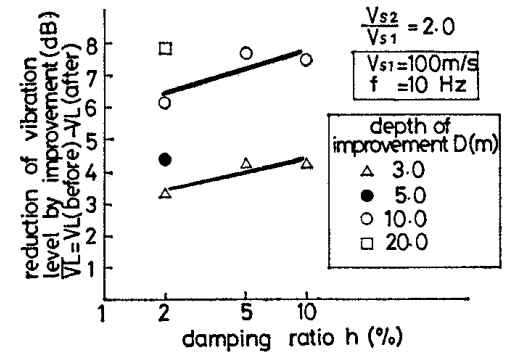

Fig. 19. Effects of damping on the reduction of ground vibrations $150 \mathrm{~m} / \mathrm{s}$, both are almost same.

Fig. 18 shows the effect of frequency on the reduction of ground vibrations. It can be noted from Fig. 18 that the reduction is almost independent of frequency in the range of $3 \sim 20 \mathrm{~Hz}$ which corresponds to the predominant frequency of traffic-induced vibrations in the case that the depth of improvement is less than $10 \mathrm{~m}$ and it slightly increases in the case that the depth of improvement is larger than $10 \mathrm{~m}$.

Fig. 19 illustrates the effect of damping on the reduction of vibrations. This figure indicates that the reduction of vibrations slightly grows up with the increase of damping ratio of the ground in the range of $2 \sim 10 \%$. Fig. 17 provides the reduction of vibrations in the case of $2 \%$ damping ratio and so some correction is required in using Fig. 17 in the case of other damping ratio than $2 \%$. 
Fig. 17 shows the results of sinusoidally fluctuating vibrations and the actual trafficinduced vibrations are not strictly sinusoidal. However according to the measurement of actual traffic-induced vibrations (Taniguchi and Sawada, 1979), Fourier spectrum of traffic-induced vibrations has a sharp peak at the natural frequency of the ground. Therefore it is possible to use approximation of treating the traffic-induced vibrations as sinusoidal oscillations.

From discussions mentioned above it can be concluded that Fig. 17 is practically useful to predict the reduction of ground vibrations due to car traffic by improving soft ground.

\section{CONCLUSIONS}

Following conclusions were obtained by the field tests and the finite element analyses described here.

i) The improvement of soft ground is effective not only to increase the bearing capacity of the ground but also to reduce the ground vibrations generated by the dynamic load applied on the ground surface. The acceleration at the ground surface was decreased to $10 \sim 60 \%$ in the frequency range less than $10 \mathrm{~Hz}$ by the ground improvement by means of lime pile method with depth of $12 \mathrm{~m}$.

ii) The width of the improvement area has small influence and the depth of the improvement area and the ratio of rigidity before and after improvement have large influence on the reduction of ground vibrations.

iii) The predominant frequency of the ground was slightly increased by the construction of lime piles in the ground.

iv) The calculated acceleration by the finite element analysis well agreed with measured values in the field tests. Therefore it is possible to simulate the ground vibration generated by a dynamic load on the ground surface by the finite element analysis.

v) The reduction of traffic-induced vibrations at the soft ground area by the ground improvement can be evaluated by using Fig. 17 that was made up by the finite element calculation.

\section{ACKNOWLEDGMENTS}

The authors would like to express their appreciation to the staff of Chugoku Regional Office of the Ministry of Construction for their cooperation in the field tests. A special thanks goes to Mr. H. Ogasawara of Public Works Research Institute for his help in the analysis of the field test data.

\section{NOTATION}

$A=$ acceleration at any point

$A_{0}=$ calculated acceleration at a distance of $1 \mathrm{~m}$ from the source

$A_{1}=$ acceleration at a distance of $r_{1}$ from the source

$f=$ frequency

$h=$ damping ratio

$L_{10}=10 \%$ value from the top of accumulation distribution

$n=$ coefficient of geometrical damping

$R=$ amplitude of applied force

$r=$ distance from source

$S=$ cross area of embankment

$t=$ time

$u=$ horizontal displacement 
$\mathrm{VL}=$ vibration level

$\overline{\mathrm{VL}}=$ reduction of VL by soft ground improvement

$\mathrm{VL}(1)=$ vibration level in the case of test truck moving in the outside lane

$V_{P}=$ propagation velocity of $\mathrm{P}$ wave

$V_{S}=$ propagation velocity of $\mathrm{S}$ wave

$V_{S_{1}}=$ propagation velocity of $S$ wave before ground improvement

$V_{S 2}=$ propagation velocity of $S$ wave after ground improvement

$V_{R}=$ propagation velocity of the Rayleigh wave

$v=$ vertical displacement

$\alpha=$ attenuation coefficient

$\Delta L_{10}=$ the reduction of $L_{10}$ at toe of the road embankment by construction of embankment road

$\Delta T=$ time interval of the input data

$\omega=$ circular frequency

\section{REFERENCES}

1) Lamb, H. (1904): "On the propagation of tremors over the surface of an elastic solid," Philosophical Transactions of the Royal Society, London, Ser. A. Vol. 203, pp.1-42.

2) Lysmer, J., Udaka, T., Seed, H. B. and Hwang, R. (1974): "LUSH, A computer program for complex response analysis of soil-structure systems," Report No. EERC74-4, University of California.

3) Narita, N. and Katsuragi, M. (1978): “Traffic-induced vibrations," Journal of JSCE, Vol.63, No. 2, pp. 43-52 (in Japanese).

4) Richart, F.E., Jr., Hall, J.R. and Woods, R.D. (1970): "Vibrations of soils and foundations," Prentice-Hall.

5) Sasaki, Y., Taniguchi, E., Ogasawara, H. and Tateyama, S. (1979): “Vibration characteristics of the improved ground," Technical Memorandum of PWRI, No.1483 (in Japanese).

6) Sawada, K., Taniguchi E., Ogasawara, H. and Tateyama, S. (1976): “Traffic-induced vibrations in soft ground (No.1)," Technical Memorandum of PWRI, No.1511 (in Japanese).

7) Taniguchi, E., Ogasawara, H. and Sawada, K. (1978): "Effects of shear strain on the dynamic deformation coefficients of clays," Proceedings of the 5 th Japan Earthquake Engineering Symposium, Tokyo, pp.705-712.

8) Taniguchi, E. and Sawada, K. (1979): "Attenuation with distance of traffic-induced vibrations," Soils and Foundations, Vol. 19, No.2, pp.15-28.

9) Taniguchi E., Sasaki, Y. and Tateyama, S. (1980): "Countermeasure to traffic-induced vibrations," Proceedings of Annual Meeting of JSCE, Kanto District, pp.155-156 (in Japanese).

10) Taniguchi E. (1980): "Investigations on the propagation characteristics of traffic-induced vibrations," Doctoral Dissertation, Kyoto University.

\section{APPENDIX}

Acceleration level VAL ( $\mathrm{dB}$ ) is defined as follows:

$$
\mathrm{VAL}=20 \log _{10} \frac{A_{e}}{A_{r}}
$$

where $A_{e}=$ effective value of acceleration, $A_{r}=$ reference value of acceleration $\left(10^{-3} \mathrm{~cm} / \mathrm{s}^{2}\right)$. Vibration level VL can be obtained by applying the human body response filter defined by JIS C 1510 to VAL.

(Received August 28, 1980) 